\title{
Remote sensing of marine oil slicks with hyperspectral camera and an extended database
}

\author{
Françoise Viallefont-Robinet, ${ }^{\text {a, } *}$ Laure Roupioz $\odot,{ }^{\text {a }}$ Karine Caillault $\odot$, \\ and Pierre-Yves Foucher $\oplus^{a}$ \\ ${ }^{a}$ ONERA DOTA Université de Toulouse, Toulouse, France \\ ${ }^{\mathrm{b}}$ ONERA DOTA, Palaiseau Cedex, France
}

\begin{abstract}
In the field of offshore oil slicks at the sea surface, radar or optical imagery can provide much useful information. Regarding optical imagery, detection relies on the differences between the reflectance of water alone and oil-covered water. As soon as the thickness of the oil layer is large enough to induce a spectral difference between the reflectance of water and oilcovered water, spectral indices are good candidates for detection. Thereafter, identification and quantification require extended optical and physical knowledge regarding oil properties. To this end, various products have been characterized in the laboratory. Hyperspectral reflectance and transmission measurements have been performed for various pure or emulsified products. This has enabled the definition of two theoretical thickness boundaries: a minimal thickness leading to a noticeable spectral attenuation effect on the reflectance between oil and water and a maximal thickness after which the spectral reflectance no longer evolves with thickness. For some products, these theoretical minimal and maximal thicknesses may not be realistic values for slicks at the sea surface, meaning that they will never be reached. However, they do give a thickness range in which thickness assessment could be performed with optical imagery and modeling. To go deeper into the understanding of oil behavior at sea, experimentation has also been done using a large tank filled with sea water, thus providing more realistic spectral signatures than in the laboratory. From this experiment, the thickness of a small amount of oil freely spread on a plane water surface has been assessed and compared with the boundaries established using the laboratory measurements. The database of spectral signatures built for product identification has been extended with the thickness boundaries and the experimental thicknesses for quantification purpose. This database has been successfully used to identify a product detected on an airborne hyperspectral image and to assess the corresponding oil slick volume, in the case of the NOFO2015 emulsion. () The Authors. Published by SPIE under a Creative Commons Attribution 4.0 Unported License. Distribution or reproduction of this work in whole or in part requires full attribution of the original publication, including its DOI. [DOI: 10.1117/1.JRS.15.024504]
\end{abstract}

Keywords: oil detection; hyperspectral signature; slick thickness.

Paper 200700 received Sep. 24, 2020; accepted for publication Mar. 17, 2021; published online Apr. 9, 2021.

\section{Introduction}

Already in the 1990s, remote sensing had been described as a promising way to improve oil spill response efforts. ${ }^{1}$ Slicks detection relies on imagery, with sensors adding information to that collected by the human eye. Sensors offer access to ultraviolet, near infrared (NIR), middle infrared (MIR), and thermal infrared (TIR) for the optical domain, as well as to several radar bands. Oil impact has no strong spectral characteristics in the visible region; $;^{1,2}$ the main hydrocarbons spectral features are absorption peaks related to $\mathrm{C}-\mathrm{H}$ absorption bands in the shortwave infrared (SWIR), MIR, and TIR domains. With the availability of hyperspectral sensors, SWIR is proving an interesting spectral range for oil detection, characterization, and quantification. In this spectral region, absorption peaks ${ }^{3}$ are found around $1.7,2.3$, and $2.6 \mu \mathrm{m}$, respectively. Oil characteristics led to indices development, ${ }^{4,5}$ and with sensors covering the visible to near-infrared (VNIR) spectral range, it is possible to identify the spectral change associated directly with oil-covered

*Address all correspondence to Françoise Viallefont-Robinet, francoise.viallefont@onera.fr 
water: the decrease of reflectance for blue wavelength and its stability in the NIR. This was described as a spectral rotation by Lennon et al. ${ }^{6}$ They used this spectral feature to build indices dedicated to oil detection with VNIR imaging systems and tested them on CASI data acquired over the Prestige tanker oil spill in November 2002. The BP Deepwater Horizon oil spill in 2010 boosted the interest and study of oil slicks via remote sensing ${ }^{7,8}$ but also showed that further development and operationalization were needed. ${ }^{8}$

Detection enables the location and monitoring of a slick, but the amount of product as well as its type and status are also crucial information for choosing the right spill response. Thus, there is a need not only for a detection map but also for a thickness map and a map of type or status. The analysis of the different components contributing to the radiance measured above a slick enables the identification of the components affected by the oil transmission, dependent on thickness. ${ }^{9,10}$ This dependency is limited to a product-specific range. Indeed, the thickness must be large enough to induce a measurable spectral difference between reflectances of water and oil-covered water. For quantification purposes, it must also be thin enough to prevent photons from being absorbed before crossing the oil layer. ${ }^{7}$

Regarding the type or the status, Lammoglia and Roberto de Souza Filho ${ }^{11}$ indicate that different oil types can be qualitatively distinguished from spectral features in the VNIR-SWIR domain.

In this context, in 2014, the NAOMI (New Advanced Observation Method Integration) project was set between TOTAL and ONERA aiming at, for its offshore part, detection, characterization, and quantification of oil slicks. Radar and/or VNIR-SWIR imagery appeared to be a good approach for fulfilling the objectives at a reasonable cost. For the optical part of the work, the idea was close to the one described in Ref. 5, using indices for detection and retrieval of spectral signatures, relying on a library of data built up from laboratory ${ }^{12}$ or in the field measurements, for characterization. Modeling of radiance for water and oil-covered water was started for quantification.

The work began with laboratory measurements providing reflectance and a crucial intrinsic pure oil parameter: the attenuation coefficient. Then, oil spills data were acquired in a tank filled with sea water and, for one of them, also at sea. The tank experiment was designed to obtain realistic spectral signatures and thicknesses. This paper focuses on the database and its use for product identification and quantification and demonstrates the interest in extending the spectral signature database with thickness information.

Section 2 defines the measured optical quantities. Section 3 deals with the material, ranging from laboratory, tank, and sea data and leading on to the extended database. Section 4 describes the methods for detection, identification, and quantification, the last two using the extended database. Section 5 presents the corresponding results for spills in both the tank and at sea. A discussion of the results can be found in Sec. 6 before the conclusion in Sec. 7.

\section{Definition of the Physical Quantities}

The relevant optical property for remote sensing optical sensors is reflectance. More precisely, for remote sensing of water, reflectance is often the spectral remote sensing reflectance. It is defined by the ratio of the water leaving radiance to the irradiance on the surface. ${ }^{13}$

In our case, the considered quantity is the bi-conical reflectance factor ${ }^{14}$ (BCRF), which is, by definition, the ratio of the reflected flux to the flux that would be reflected by an ideal perfectly diffuse standard surface illuminated by a collimated source. It corresponds to the reflectance of a Lambertian opaque surface leading to the radiance observed at the sensor level.

For non-opaque products, reflectance is background- and thickness-dependent; therefore it is not an intrinsic parameter. A useful intrinsic parameter for product characterization is the spectral attenuation coefficient corresponding to the sum of spectral absorbance and scatterance per distance unit. ${ }^{13}$

It is noteworthy that BCRF is a dimensionless quantity. If the conical apertures are small enough to consider that bidirectional reflectance distribution function (BRDF) is constant over these small angular domains (which is often the case except for the specular reflection direction), BCRF is simply equal to BRDF $\left(\mathrm{sr}^{-1}\right)$ multiplied by $\pi(\mathrm{sr})$ and BCRF is equal to the bidirectional reflectance factor. 


\section{Materials}

The list of the studied products and associated measurements is given in Table 1. The following sections describe the measurements and the information derivation for the extended database.

\subsection{Data Coming from Laboratory Measurements}

Transmission measurements were performed with a PerkinElmer spectrophotometer, taking into account the reflection at each interface. ${ }^{12}$ Each product was poured into a quartz cell with a thickness that was adapted to the product. These measurements enabled us to derive the attenuation coefficient and then from the attenuation coefficient, a theoretical minimal thickness that induces a spectral attenuation effect on reflectance between oil and water and a theoretical maximal thickness beyond which spectral reflectance no longer evolves with thickness.

Concerning reflectance, measurements were performed with the ONERA spectrogoniometer dedicated to large samples ("Banc de BRDF Grands Echantillons") as shown Fig. 1. It covers the 0.35 - to $2.5-\mu \mathrm{m}$ spectral range with a $3-\mathrm{nm}$ spectral resolution in the VNIR $(0.35$ to $1 \mu \mathrm{m})$ and $10 \mathrm{~nm}$ in the SWIR (1 to $2.5 \mu \mathrm{m})$ spectral ranges from an ASD Fieldspec spectroradiometer. The zenith angles of the source (SZA) and of the spectrometer collection optics (VZA) can vary between $0 \mathrm{deg}$ and $60 \mathrm{deg}$ with an accuracy of $1 \mathrm{deg}$. The azimuthal angle of the spectrometer collection optics (VAA) can vary between 0 deg and 180 deg with an accuracy of $1 \mathrm{deg}$. Thus, the setup enables the recording of a spectral radiance for a sequence of angular configurations over nearly a full quarter of a sphere. However, due to the occultation of the source by the collection optics, measurements are not possible in the backscattering direction $\pm 10 \mathrm{deg}$. Our measurements are limited to nadir (VZA $=0 \mathrm{deg}$ ). For most of them, SZA varies from $10 \mathrm{deg}$ to $50 \mathrm{deg}$ with a step of $10 \mathrm{deg}$ for an arm angle equal to

Table 1 Products and measurements. The reflectance in italics corresponds to measurements for a unique angular configuration, and the reflectance in bold for several angular configurations as detailed in Sec. 3.1.

\begin{tabular}{|c|c|c|c|c|}
\hline Name & Description & Laboratory & Marine tank & Sea \\
\hline Colza & Rapeseed oil & Transmission, reflectance & Reflectance & \\
\hline DALIA & Crude oil from Angola & Transmission, reflectance & & \\
\hline FAME & & Transmission & Reflectance & \\
\hline Gazole & Diesel & Transmission, reflectance & Reflectance & \\
\hline HC1541 & Light crude oil & Transmission, reflectance & & \\
\hline NOFO2015 & $\begin{array}{l}\text { Emulsion: } 40 \% \text { oil and } \\
60 \% \text { sea water (oil = } \\
\text { Oseberg + TBTS) }\end{array}$ & Transmission, reflectance & Reflectance & Reflectance \\
\hline Olive & Olive oil & Transmission, reflectance & Reflectance & \\
\hline SP95 & Unleaded gas 95 E10 & Transmission & Reflectance & \\
\hline SP98 & Unleaded gas 98 & Transmission & Reflectance & \\
\hline TBTS & Heavy oil-fuel & Transmission, reflectance & Reflectance & \\
\hline Tournesol & Sunflower oil & Transmission, reflectance & Reflectance & \\
\hline UN1267 & Petroleum crude oil & Transmission & & \\
\hline USAN & Crude oil from Nigeria & Transmission, reflectance & & \\
\hline $15 \mathrm{~W} 40$ & Motor oil & Transmission, reflectance & Reflectance & \\
\hline Plantoil & $\begin{array}{l}\text { Industrial oil } \\
\text { (RADIAGREEN EBO) }\end{array}$ & Transmission, reflectance & & \\
\hline
\end{tabular}




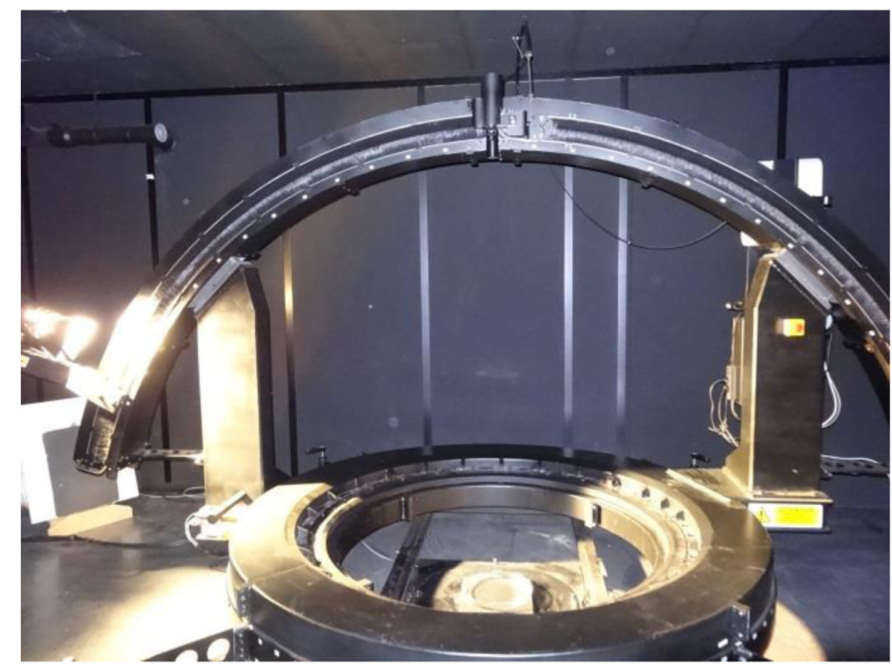

Fig. 1 ONERA spectro-goniometer dedicated to large samples (Banc de BRDF Grands Echantillons).

$180 \mathrm{deg}$ corresponding to VAA $=180 \mathrm{deg}$. For a small set of products, in italics in Table 1, measurements were performed for only one angular configuration: SZA $=40$ deg, VZA $=$ $0 \mathrm{deg}$, and VAA $=180 \mathrm{deg}$ for the arm with the collection optics. Measurements were performed for various thicknesses ranging from 4 to $10 \mathrm{~mm}$ : five thicknesses $(4,5.5,7,8.5$, and $10 \mathrm{~mm}$ ) for the small set of products in italics in Table 1 and three thicknesses $(5,7.5$, and $10 \mathrm{~mm}$ ) for the others.

For non-opaque and non-scattering products, a model of the reflectance measurement was established according to Fig. 2 and led to Eq. (1). This model, more complete than in Ref. 12, enables artificial modification of the background and thickness and therefore generation of adequate signatures.

$$
\rho=T\left(\theta_{s}\right) \cdot e^{-\frac{k \cdot e}{\cos \left(\theta_{s}^{\prime}\right)}} T\left(\theta_{s}^{\prime}\right) \cdot T\left(\theta_{s}^{\prime \prime}\right) \cdot t^{\downarrow} \cdot \rho_{b} \cdot t^{\uparrow} \cdot T\left(\theta_{v}^{\prime \prime}\right) \cdot T\left(\theta_{v}^{\prime}\right) \cdot e^{-\frac{k \cdot e}{\cos \left(\theta_{v}^{\prime}\right)}} \cdot T\left(\theta_{v}\right),
$$

where $\rho$ is the reflectance, $T\left(\theta_{s}\right)$ is the downward Fresnel transmission between air and product for an illumination zenith angle $\theta_{s}, k$ is the attenuation coefficient, $e$ is the thickness, $T\left(\theta_{s}^{\prime}\right)$ is the downward Fresnel transmission between product and container for an angle $\theta_{s}^{\prime}$ on the product side, $T\left(\theta_{s}^{\prime \prime}\right)$ is the downward Fresnel transmission between container and background for an angle $\theta_{s}^{\prime \prime}$ on the container side, $t^{\downarrow}$ and $t^{\uparrow}$ are the downward and upward transmissions within

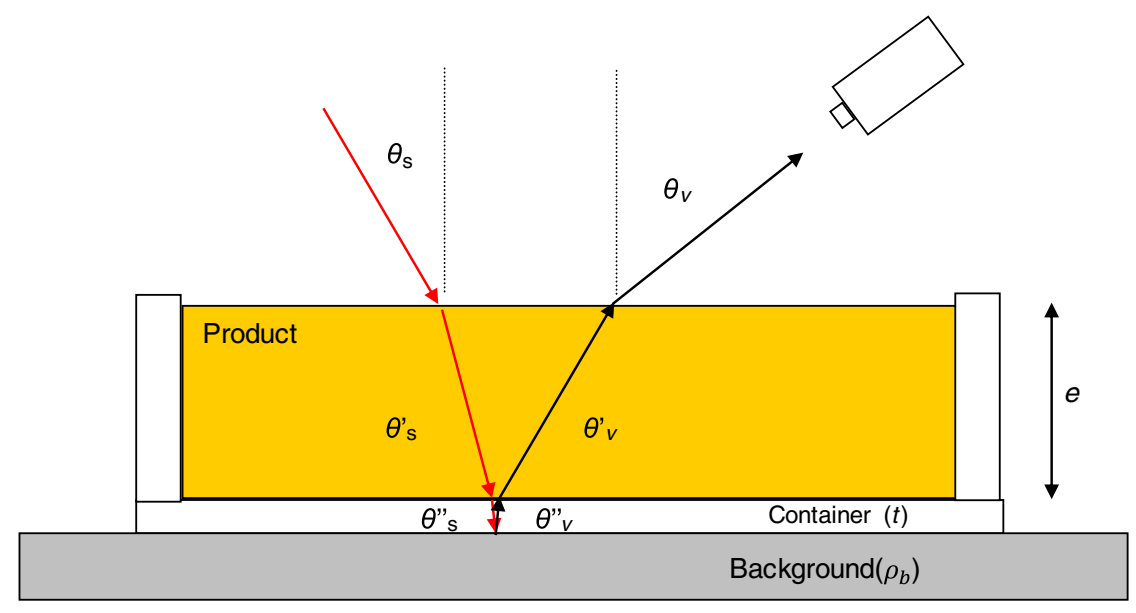

Fig. 2 Ray path used for reflectance measurement modeling for non-opaque and non-scattering products. 


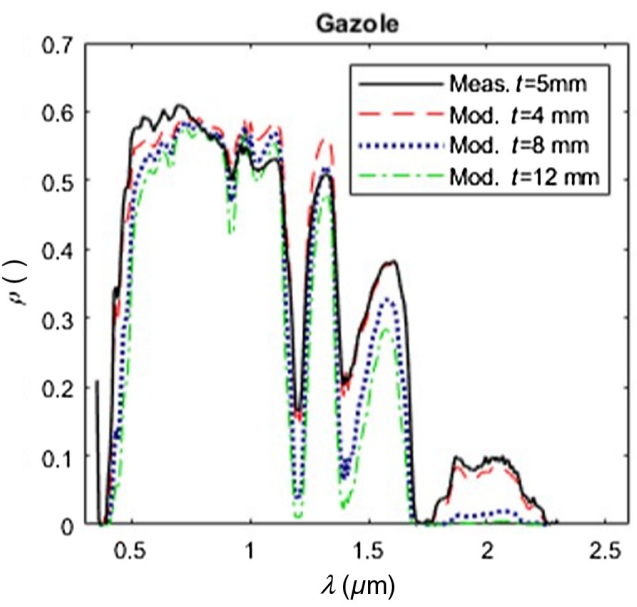

(a)

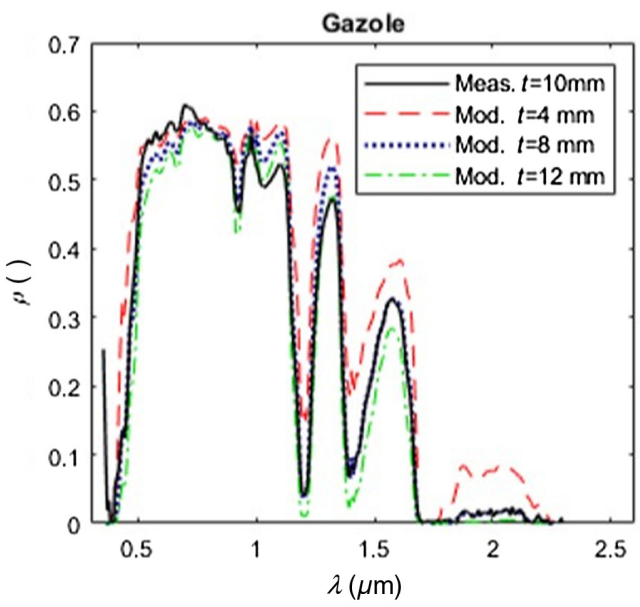

(b)

Fig. 3 Comparison of computed reflectance for sample thickness from 4 to $12 \mathrm{~mm}$ (various colors) and measured (bold black) laboratory reflectance for diesel: approximative expected diesel thickness (a) $5 \mathrm{~mm}$ and (b) $10 \mathrm{~mm}$.

the container, respectively, $T\left(\theta_{v}^{\prime \prime}\right)$ is the upward Fresnel transmission between background and container for an angle $\theta_{v}^{\prime}$ on the container side, $T\left(\theta_{v}^{\prime}\right)$ is the upward Fresnel transmission between container and product for an angle $\theta_{v}^{\prime}$ on the product side, $T\left(\theta_{v}\right)$ is the upward Fresnel transmission between product and air for an observation zenith angle $\theta_{v}$, and $\rho_{b}$ is the background reflectance. $t^{\downarrow} \cdot \rho_{b} \cdot t^{\uparrow}$ is a term corresponding to laboratory measurement. It can be replaced by a measured reflectance over clean sea water for instance. This enables the building of fairly realistic signatures. $e^{-\frac{k . e}{\cos \left(\theta_{s}^{\prime}\right)}} e^{-\frac{k e \cdot}{\cos \left(\theta_{v}^{\prime}\right)}}$ is a term depending on product thickness. It can be used to compute the reflectance for other thickness values as shown in Fig. 3.

A validation of the model and of the measurements was done for some products. The attenuation coefficient value deduced from transmission measurements was used in Eq. (1). Various constant values for the product optical index were used to compute the $T$ terms. As the actual thickness was only roughly known (measurement with a simple ruler), the computation was performed for several thickness values. The computed reflectances (colored lines) were compared with the measured one (bold black line) as shown in Fig. 3 for diesel. The expected diesel thickness (according to the ruler) is $5 \mathrm{~mm}$ in Fig. 3(a) and $10 \mathrm{~mm}$ in Fig. 3(b). This is in agreement with the model for a 4-mm and 8-mm thickness, respectively (in the SWIR region more sensitive to the thickness). This shows a fairly good agreement between model (including inputs) and measurements.

\subsection{Data Coming from Tank Filled with Sea Water}

For the measurements, a small part of a large tank $\left(1900 \mathrm{~m}^{2}\right)$ located in CEDRE (Center for Research and Experimentation for Accidental Water Pollution) at Brest, France, fairly deep $(3 \mathrm{~m})$ and filled with sea water, was used to generate successive small slicks. For each product, a known volume was poured into a frame floating on the tank as in Fig. 4(a). Two hyperspectral cameras fixed about $15 \mathrm{~m}$ above the frame imaged each slick as shown in Fig. 4(b). The features of the cameras are given in Table 2. The water surface in the frame was cleaned between each product. The cameras also imaged the Spectralon ${ }^{\odot}$ reference panels set on the quay. Computing the radiance ratio of pixels from the slick to pixels from the reference panel and multiplying this ratio by the reflectance of the reference panel provides spectral signatures. The thickness assessment is described in Refs. 15 and 16. It relies on slick detection using indices. A mean thickness is computed by dividing the volume poured in the frame by the surface of the slick. In the case of NOFO2015 mixed slick, with a thin and a thick part, the assessment is refined. From the thickness assessment of several products, a common mean thickness of $25 \mu \mathrm{m}$ has been found for light crude oil (HC1541), gasoil, and unleaded gas 98. The VNIR image [Fig. 5(a)] enables the 


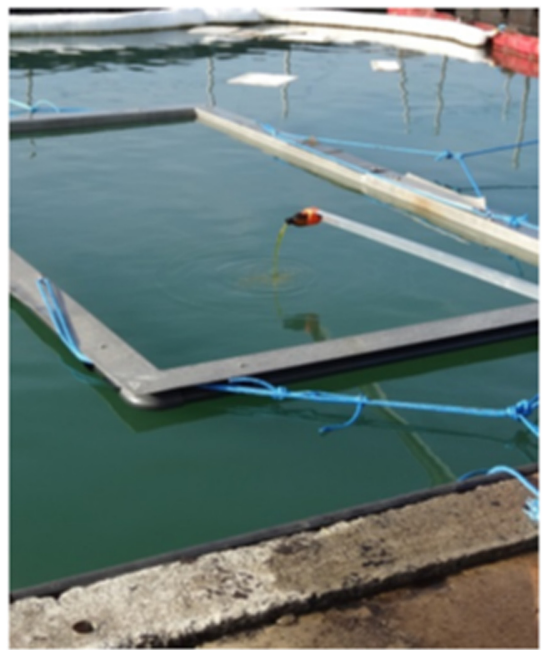

(a)

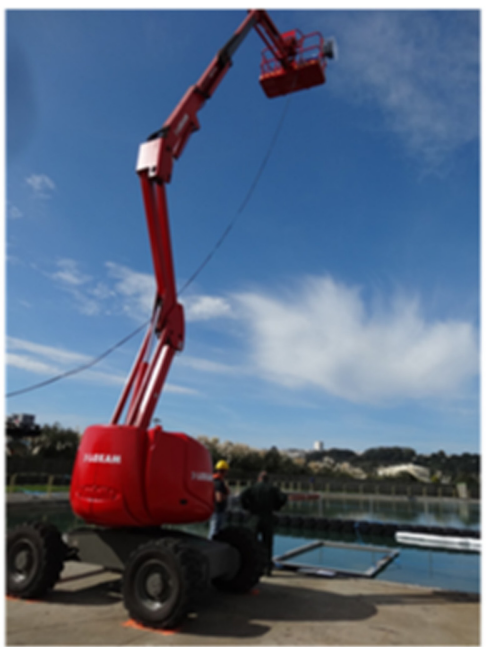

(b)

Fig. 4 Tank experiment: (a) pouring a known volume of product (rapeseed oil) and (b) imaging the slick with two hyperspectral cameras at the top of a cherry picker.

Table 2 Features of the two hyperspectral pushbroom cameras.

\begin{tabular}{lcc}
\hline \hline Features & HySpex VNIR & HySpex SWIR \\
\hline Number of pixels & 1600 & 320 \\
Field of view & $17 \mathrm{deg}$ & $14 \mathrm{deg}$ \\
Spectral range & 0.4 to $1 \mu \mathrm{m}$ & 1 to $2.5 \mu \mathrm{m}$ \\
Number of spectral bands & 160 & 256 \\
Length of spectral bands & $3.7 \mathrm{~nm}$ & $6 \mathrm{~nm}$ \\
Pixel dimensions at $15 \mathrm{~m}$ & $2.8 \mathrm{~mm} \times 5.6 \mathrm{~mm}$ & $11.3 \mathrm{~mm} \times 11.3 \mathrm{~mm}$ \\
Pixel dimensions at $9000 \mathrm{ft}$ & $0.51 \mathrm{~m} \times 1.03 \mathrm{~m}$ & $2.06 \mathrm{~m} \times 2.06 \mathrm{~m}$ \\
Swath at $9000 \mathrm{ft}$ & $820 \mathrm{~m}$ & $660 \mathrm{~m}$ \\
View & $\mathrm{Nadir}$ & $\mathrm{Nadir}$ \\
\hline \hline
\end{tabular}

detection of the whole slick, and the SWIR image [Fig. 5(b)] enables the detection of the thicker part only. The difference gives the surface covered by the thin part. Assuming a thickness of $25 \mu \mathrm{m}$ for the thinner part, the volume of this thinner part is then computed. This thinner part volume is subtracted from the total volume poured into the frame to assess the volume corresponding to the thicker part of the slick. The mean thickness of the thicker part is then assessed by dividing the volume of this part with the corresponding surface. It leads to $1.1 \mathrm{~mm}$ for the NOFO2015 emulsion thick part.

\subsection{Data Coming from Sea}

Hyperspectral imaging of marine slicks was performed in 2015 during a campaign organized by NOFO, a Norwegian entity (Norwegian Clean Seas Association for Operating Companies). The campaign objective was to test devices to clean a slick. The ONERA imaging system named SETHI onboard a FALCON20 aircraft was allowed to image the slicks during the recovery exercises. ${ }^{17}$ The optical images were acquired with the same cameras as used for the tank experiment. Their features are given in Table 2 . 


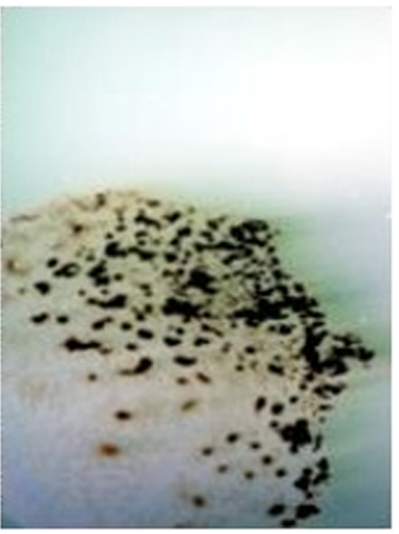

(a)

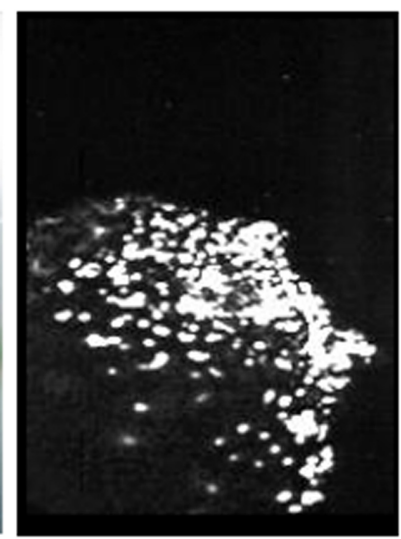

(b)

Fig. 5 NOFO2015 emulsion in the tank: (a) VNIR image and (b) SWIR image.

During the experiment corresponding to results presented in Sec. 5, the sea state was 3 on the Douglas scale.

\subsection{Extended Database}

All of the data presented previously constitutes the extended database. It contains not only spectral signatures (laboratory and/or tank and/or at sea spectral reflectance) but also the attenuation coefficient, corresponding theoretical minimal and maximal thicknesses from an optical point of view, and thickness derived from the tank experiment when available. The current content regarding thicknesses is illustrated by Fig. 6 .

In this figure, the att_MIN and att_MAX thicknesses correspond to theoretical optical boundaries computed by the attenuation coefficient. For the att_MIN, the value is taken in the SWIR domain, around $1.7 \mu \mathrm{m}$. For the att_MAX, it is taken either in SWIR (for UN1267, TBTS, NOFO2015 emulsion, HC1541, DALIA, USAN which includes all crude oils) or in VNIR (for the others) depending on the spectral shape of the attenuation coefficient and its availability (some of our measurements, for very opaque oils, were not reliable for wavelengths $<0.7 \mu \mathrm{m}$ ). Considering only the VNIR domain would probably lead to much smaller att_MAX values for

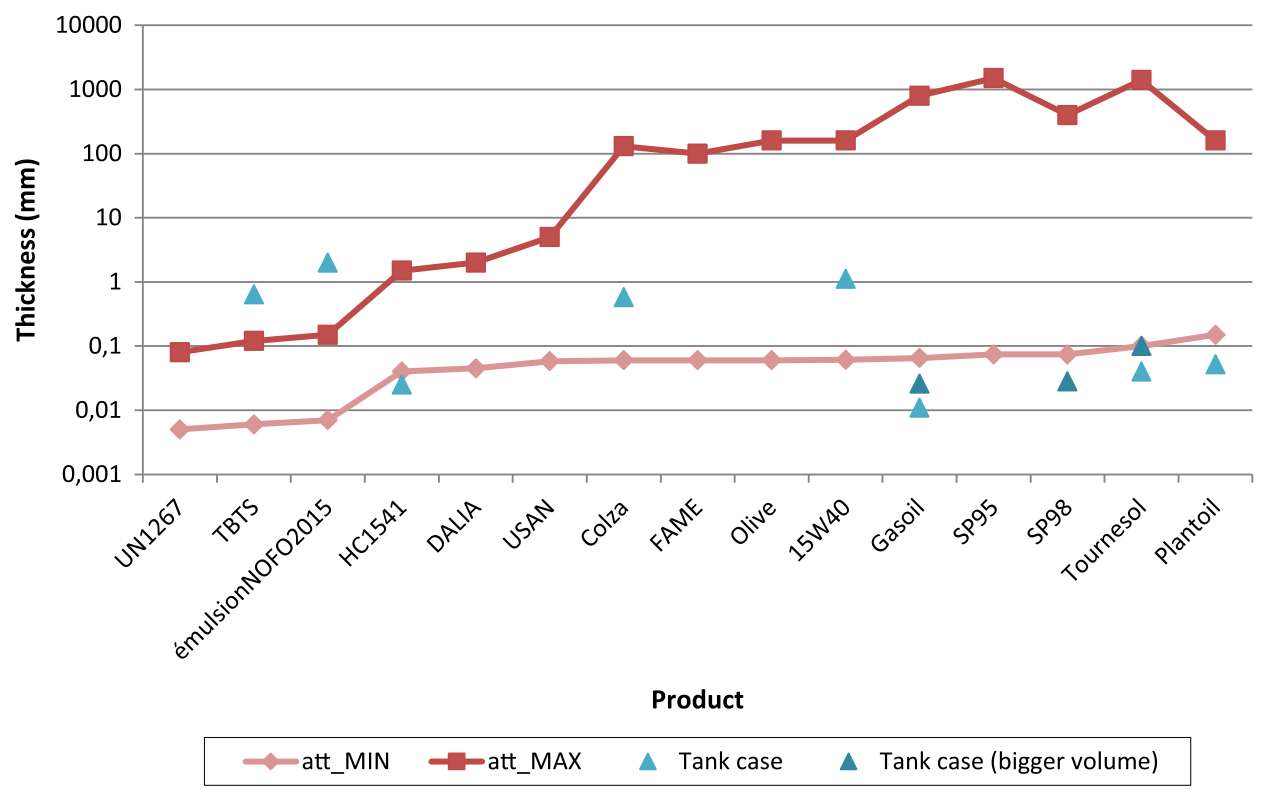

Fig. 6 Illustration of the extended database content for thicknesses. 
all crude oils in agreement with values from Ref. 10. The att_MAX thickness corresponds to the theoretical skin depth and represents the largest thickness that enables ray crossing of the full layer above the water, forward and backward. For thicknesses larger than att_MAX, the deepest part of the layer does not contribute to the measured reflectance; therefore reflectance cannot be inverted with an optical model to restitute the thickness. The att_MIN value represents the theoretical smallest thickness that induces a detectable spectral attenuation for ray crossing the full layer forward and backward. It is noteworthy that slicks with smaller thicknesses than att_MIN may be detectable due to other phenomena (index difference between product and water and possible interferences).

The thicknesses observed in our tank experiment correspond to the blue triangles. The experimental thickness is in the att_MIN-att_MAX range for only two cases (Colza and 15W40). This means that, for these two cases, the spectral reflectance and optical model looking at attenuation could theoretically enable one to assess thickness. For TBTS and emulsionNOFO2015 cases, the actual thickness is above the att_MAX; therefore thickness cannot be derived from an optical model. For the other cases (HC1541, Gasoil, SP98, Tournesol, and Plantoil), the actual thickness is smaller than the att_MIN, and thickness cannot be derived from attenuation terms of an optical model. In several cases, for highly transparent oils, such as unleaded gas, the att_MAX values are very high and, of course, the actual thickness is expected to be much lower than this theoretical boundary. The whole content is summarized in Table 3.

Table 3 Overview of the extended database content. $L$ corresponds to laboratory measurement, $T$ to tank experiment measurements, and $S$ to measurements at sea. As in Table 1, the italic $L$ corresponds to the case with only one angular configuration. $Y$ stands for yes and indicates that information is present. $\mathrm{N}$ stands for no and indicates that information is not present.

\begin{tabular}{|c|c|c|c|c|}
\hline Name & Description & $\begin{array}{c}\text { Spectral } \\
\text { reflectance } \\
(\text { VNIR + SWIR) }\end{array}$ & $\begin{array}{l}\text { Attenuation coefficient } \\
\text { and att_MIN and } \\
\text { att_MAX thicknesses }\end{array}$ & $\begin{array}{c}\text { Thickness } \\
\text { deduced from } \\
\text { tank experiment }\end{array}$ \\
\hline Colza & Rapeseed oil & $\mathrm{L}, \mathrm{T}$ & Y & $\mathrm{Y}$ \\
\hline DALIA & Crude oil from Angola & $L$ & Y & $\mathrm{N}$ \\
\hline FAME & & $\mathrm{T}$ & $\mathrm{Y}$ & $\mathrm{N}$ \\
\hline Gazole & Diesel & $L, T$ & Y & $\mathrm{Y}$ \\
\hline HC1541 & Light crude oil & $\mathrm{L}, \mathrm{T}$ & $\mathrm{Y}$ & Y \\
\hline NOFO2015 & $\begin{array}{l}\text { Emulsion: } 40 \% \text { oil and } \\
60 \% \text { sea water } \\
\text { (oil = Oseberg + TBTS) }\end{array}$ & L, T, S & Y & $\mathrm{Y}$ \\
\hline Olive & Olive oil & $\mathrm{L}, \mathrm{T}$ & $\mathrm{Y}$ & $\mathrm{N}$ \\
\hline SP95 & Unleaded gas 95 E10 & $\mathrm{T}$ & $\mathrm{Y}$ & $\mathrm{Y}$ \\
\hline SP98 & Unleaded gas 98 & $\mathrm{~T}$ & Y & $\mathrm{N}$ \\
\hline TBTS & Heavy oil-fuel & $\mathrm{L}, \mathrm{T}$ & $\mathrm{Y}$ & Y \\
\hline Tournesol & Sunflower oil & $\mathrm{L}, \mathrm{T}$ & $\mathrm{Y}$ & Y \\
\hline UN1267 & Petroleum crude oil & $\mathrm{N}$ & $\mathrm{Y}$ & $\mathrm{N}$ \\
\hline USAN & Crude oil from Nigeria & $L$ & $\mathrm{Y}$ & $\mathrm{N}$ \\
\hline $15 \mathrm{~W} 40$ & Motor oil & $\mathrm{L}, \mathrm{T}$ & $\mathrm{Y}$ & $\mathrm{Y}$ \\
\hline Plantoil & $\begin{array}{l}\text { Industrial oil } \\
\text { (RADIAGREEN EBO) }\end{array}$ & $\mathrm{L}, \mathrm{T}$ & $\mathrm{Y}$ & $Y$ \\
\hline
\end{tabular}

Note: Access to data from the extended database is possible. For that, an official and named request per user, mentioning which data are requested and their foreseen use, should be addressed to TOTAL ${ }^{18,19}$ and to ONERA. ${ }^{20,21}$ 
Viallefont-Robinet et al.: Remote sensing of marine oil slicks with hyperspectral camera...

Table 4 Definition of spectral indices. $\rho$ stands for reflectance, and numbers correspond to wavelength expressed in micrometer.

\begin{tabular}{lllc}
\hline \hline \multicolumn{1}{c}{ Index } & \multicolumn{1}{c}{ Definition } & Reference \\
\hline VNIR & FI: fluorescence index & $\left(\rho_{0.47}-\rho_{0.67}\right) /\left(\rho_{0.47}+\rho_{0.67}\right)$ & 6 \\
& RAl: rotation-absorption index & $\|\rho\|\left(\rho_{0.47}-\rho_{0.85}\right) /\left(\rho_{0.47}+\rho_{0.85}\right)$ & 6 \\
& $\mathrm{nFI}:$ normalized FI & $\|\rho\|\left(\rho_{0.47}-\rho_{0.67}\right) /\left(\rho_{0.47}+\rho_{0.67}\right)$ & 17 \\
SWIR & $\mathrm{HI}:$ hydrocarbon index & $\frac{(1.72-1.67)}{(1.75-1.67)}\left(\rho_{1.75}-\rho_{1.67}\right)+\rho_{1.67}-\rho_{1.72}$ & 4 \\
& Aire 1700 & $\begin{array}{l}\text { Surface under the reflectance curve } \\
\text { between 1.66 and 1.75 } \mu \mathrm{m}\end{array}$ & 22 \\
& Aire 2300 & $\begin{array}{l}\text { Surface under the reflectance curve } \\
\text { between } 2.21 \text { and } 2.38 \mu \mathrm{m}\end{array}$ & 22 \\
& &
\end{tabular}

\section{Methods}

\subsection{Detection}

Detection relies on spectral indices that correspond to spectral band ratio or linear combination. The definitions of the indices used in this paper are provided in Table 4. An index image is computed for each case. The corresponding histogram is used to separate water and oil.

\subsection{Identification}

Product identification is performed from spectral libraries. Spectral reflectances collected in the laboratory constitute the lab spectral library, and the ones collected during the tank experiment constitute the tank spectral library.

For the non-opaque and non-scattering products, the laboratory model was used to replace the background used for the laboratory measurements with the water of the tank.

Three spectral distances were selected to compare the image with the libraries: Spectral Information Divergence (SID), ${ }^{23}$ Spectral Angle Mapper (SAM), ${ }^{23}$ and CHI2. A threshold can be given by the user to limit the classification to really similar spectra.

\subsection{Quantification}

For identified products, volume assessment can be done due to thickness being deduced from signature adjustment (by adjusting the exponential terms as explained in Sec. 3.1) or using the thickness stored in the database. Knowing the pixel size for the image, the surface covered by the product is simply computed as the product of the number of pixels found by the detection tool with the pixel size. This surface is multiplied by the thickness found by signature adjustment or associated with the product in the database:

$$
V=N \cdot p_{r} \cdot p_{c} \cdot e,
$$

where $V$ is the product volume, $p_{r}$ is the pixel size in the row direction, $p_{c}$ is the pixel size in the column direction, and $e$ is the product thickness. The slick may be separated into a thin and a thick part. In this case, the volume for each part is assessed according to Eq. (2), and the total volume is computed by summation.

\section{Results}

The results correspond to images from the tank experiment and to an airborne image acquired during the NOFO2015 campaign. For the sake of consistency, only results obtained for the 
NOFO2015 emulsion will be presented, as data are available at all scales, from laboratory to real sea conditions.

\subsection{Detection}

\subsubsection{Tank experiment case}

Figure 7 shows the results for the various detection indices and automatic thresholding in the case of NOFO2015 emulsion in the tank. The three VNIR indices enable the detection of the whole slick, whereas the SWIR indices enable the detection of its thick part. For VNIR indices, the automatic thresholding can also be applied to the slick itself to distinguish its thin and thick parts.

\subsubsection{Sea case}

The detection result for an airborne image is presented in Fig. 8 for VNIR indices and in Fig. 9 for SWIR ones. In these figures, the upper part corresponds to the indices images, and just below are the corresponding detection masks generated with automatic thresholding on the indices images. The lower part corresponds to the histograms of indices images with the threshold found. Only FI enables the detection of the whole slick for the marine tank. RAI and nFI seem to detect only the thicker emulsified part. For the SWIR indices, they seem to detect the very thick part of the slick and the automatic thresholding reinforces the underdetection. The automatic thresholding on the FI index has been applied to the slick itself to distinguish its thin and thick parts.

\subsection{Identification}

\subsubsection{Tank experiment case}

Figure 10 shows the results for the identification step in the case of NOFO2015 emulsion in the tank using, respectively, the tank library for the upper part and the lab library for the lower part of
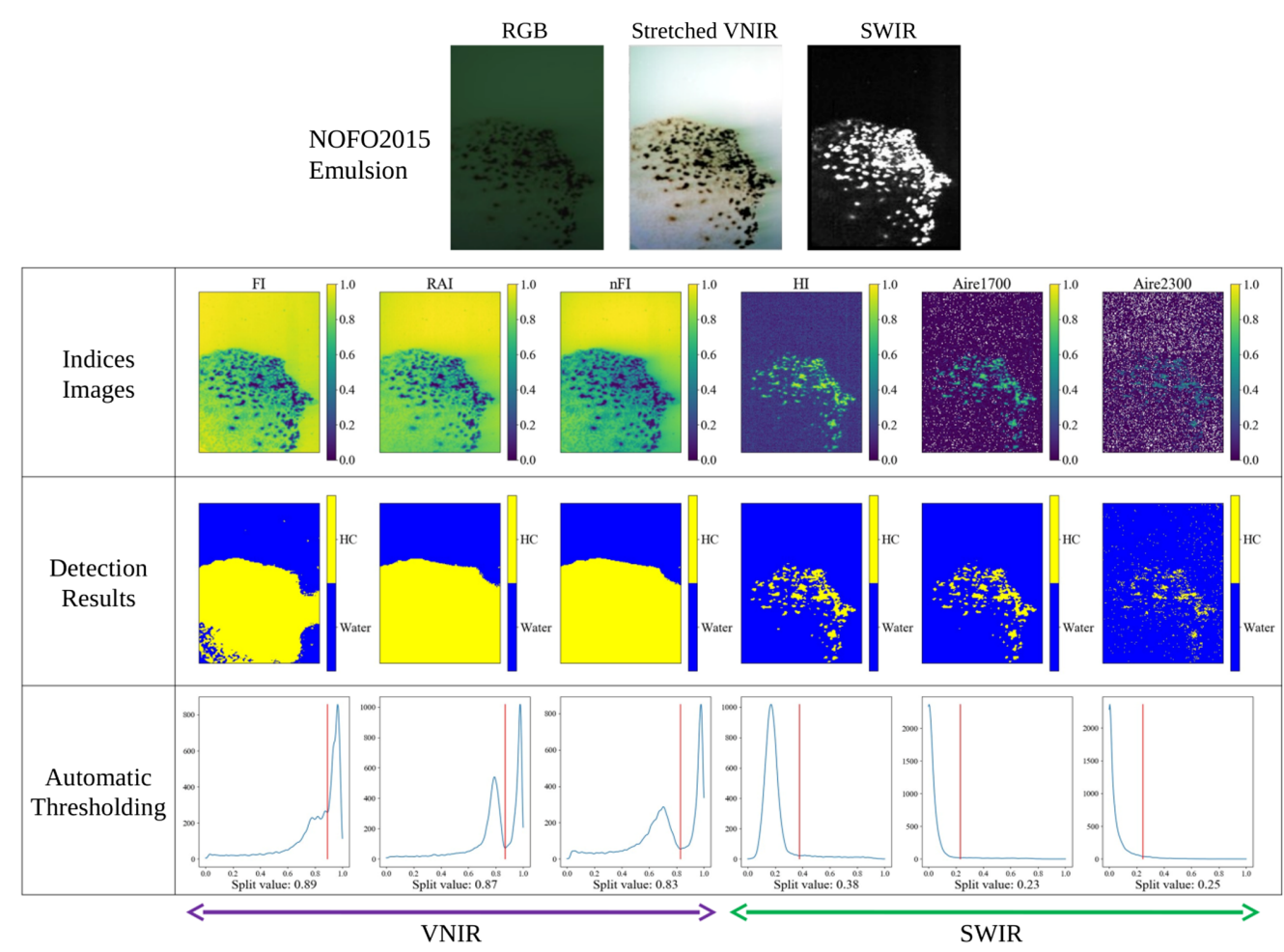

Fig. 7 Comparison of detection results for various indices for NOFO2015 emulsion in the tank. 

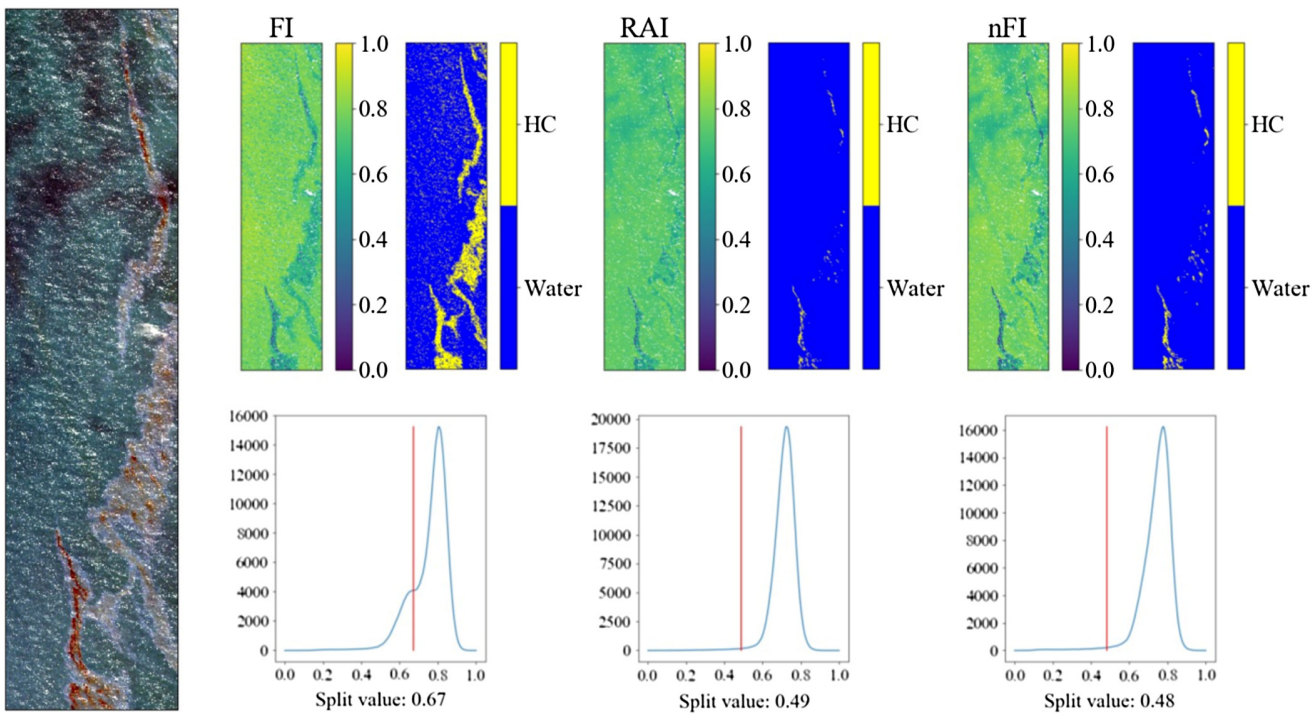

Fig. 8 Comparison of detection results for various VNIR indices for NOFO2015 emulsion at sea.
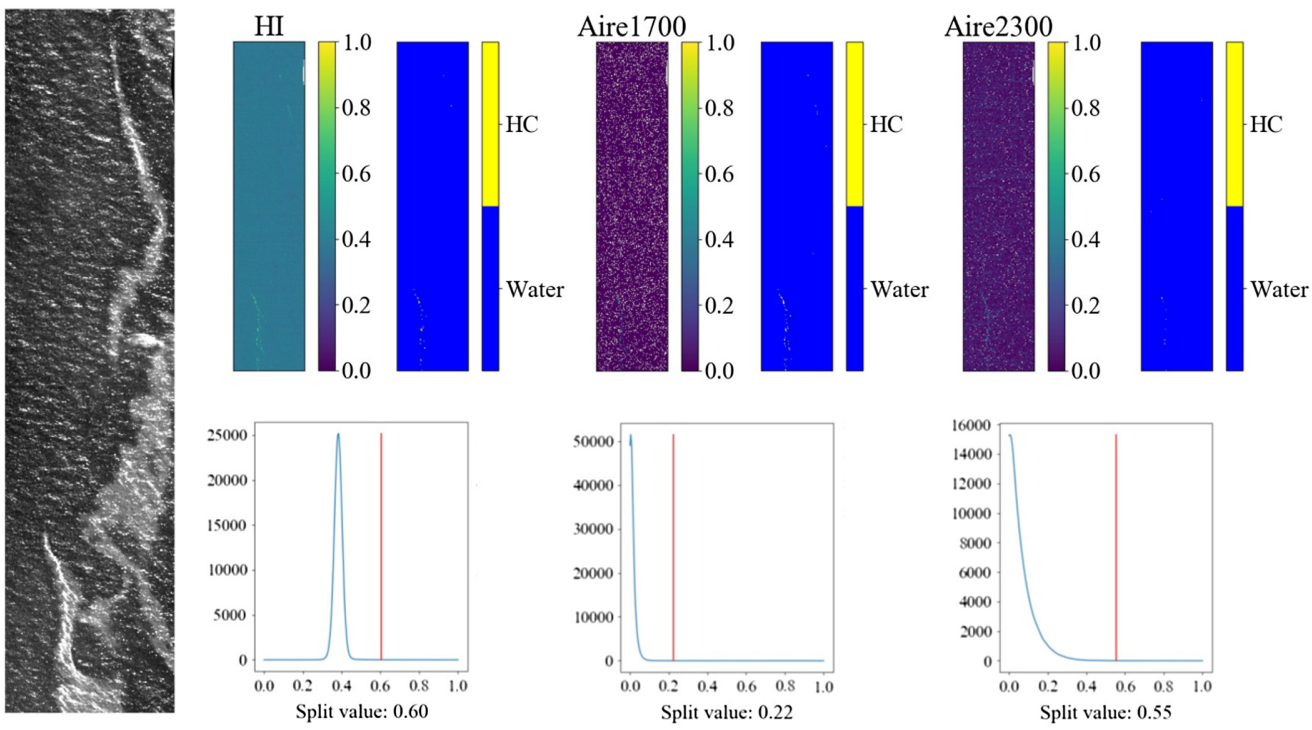

Fig. 9 Comparison of detection results for various SWIR indices for NOFO2015 emulsion at sea.

the figure. In the lab library case, SAM, CHI2, and SID enable the identification of the thicker part of the slick. In the tank library case, a signature for the thinner part of the slick is included, which enables the detection of this part, but for the thicker part, the identification seems to be less efficient than for the lab library. For some pixels, there is confusion with sunflower oil. Figure 11 illustrates the content of each library.

\subsubsection{Sea case}

In the sea case, the identification has to be limited to the very thick part. For this part, the percentage of correctly identified pixels is $82 \%$ for CHI $2,86 \%$ for SAM, and $88 \%$ for SID.

\subsection{Quantification}

Once the product is identified, the volume can be computed. In the NOFO2015 emulsion case, as explained in Ref. 15, light cannot reach the bottom of the emulsion layer and go back to the 


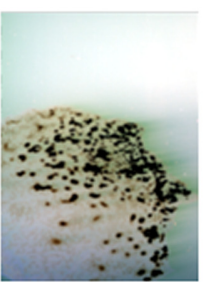

VNIR

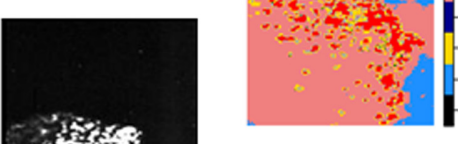

SAM

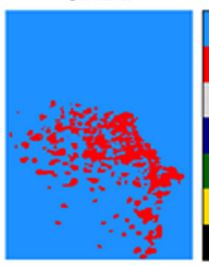

CHI2

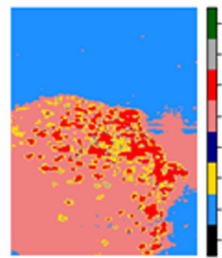

CHI2

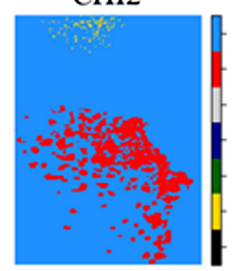

SID

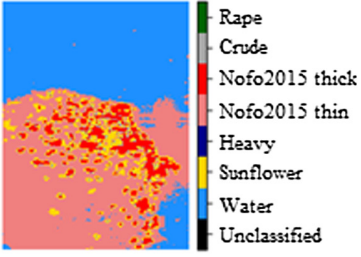

SID

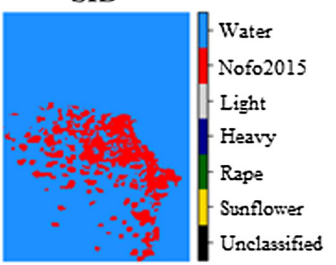

Fig. 10 Comparison of identification results for various spectral distances for NOFO2015 emulsion in the tank using the tank library (upper part) and the lab library (lower part).

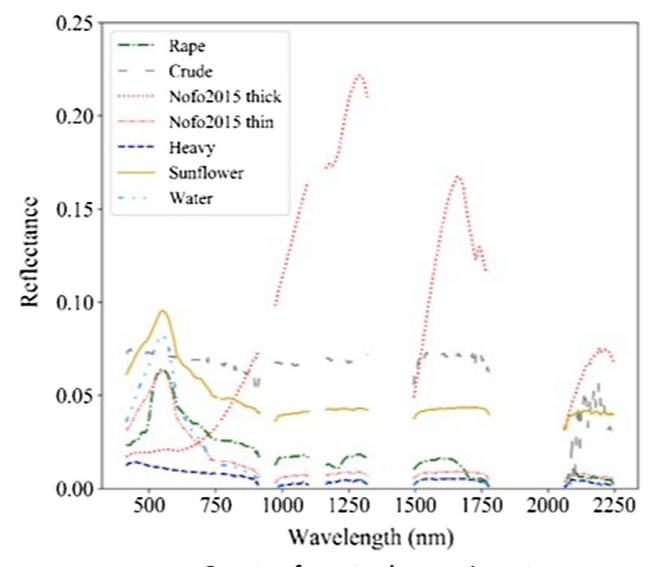

Spectra from tank experiment

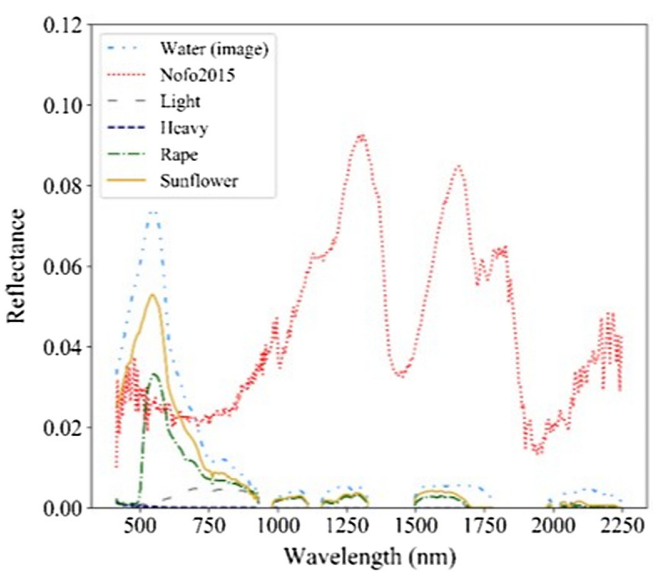

Spectra derived from laboratory measurements

Fig. 11 Tank and lab libraries used for results presented in Fig. 10.

sensor. Therefore, the thickness cannot be determined only by the analysis of the in situ spectral reflectance with an optical model (cf Sec. 3.1). The mean thickness observed in the tank is taken as the best estimate of the mean thickness of the slick at sea. According to the tank experiment, the mean thickness for the thinner part of the slick is assumed to be equal to $25 \mu \mathrm{m}$ and it leads to $1.1 \mathrm{~mm}$ for its thicker part. The corresponding result for the airborne image of the NOFO2015 campaign is presented in Table 5.

Table 5 Slick surface and volume for the NOFO2015 airborne image.

\begin{tabular}{lccc}
\hline \hline & Thick & Thin & Total \\
\hline Surface $\left(\mathrm{m}^{2}\right)$ & 13,533 & 109,007 & 122,540 \\
Volume $\left(\mathrm{m}^{3}\right)$ & 14.9 & 2.7 & 17.6 \\
Surface $(\%)$ & 11 & 89 & 100 \\
Volume $(\%)$ & 85 & 15 & 100 \\
\hline \hline
\end{tabular}




\section{Discussion}

In the previous section, results concerning the NOFO2015 emulsion were presented. In this section, the representativeness of the database content in terms of signatures and thicknesses is discussed. The volume assessment for the NOFO2015 emulsion case is compared with the one relying on photointerpretation and Bonn code.

\subsection{Database Content Representativeness}

\subsubsection{Spectral signatures}

For non-emulsified products, up to now, spectral signatures correspond to a flat water surface, which is far from the real sea water surface. This impacts the magnitude of the reflectance and therefore the contrast between oil and water. Modeling has been developed to assess the spectral signature for a flat and a real sea surface covered with oil. This will enable us to produce a realistic signature for various spatial resolutions.

For emulsified products, modeling of the signature for water-in-oil emulsion on a flat surface is still in progress.

\subsubsection{Thicknesses}

As for the signature, the thicknesses are assessed for a flat water surface. At sea, the wind and the waves elongate the slick. This phenomenon tends to reduce its thickness. But the Langmuir circulation tends to concentrate the slick in the perpendicular direction. This concentration is less effective for high viscosity oil. ${ }^{24}$ The balance between the two effects is difficult to assess. These existing contrasting effects, lead us to the conclusion that the thickness derived from the tank experiment can be considered a reasonable approximation of the actual thickness.

In the case of the NOFO2015 emulsion slick in the marine tank, the thin part of the slick looks like light crude oil. The Oseberg blend included in the NOFO2015 emulsion has not been characterized on its own in the lab or in the tank. The products leading to a $25-\mu \mathrm{m}$ thickness during the tank experiment, including a light crude oil, were detected visually but not with the index. Therefore, the thickness of the thin part of the slick could be higher than $25 \mu \mathrm{m}$, and this would decrease the value found for the thicker part of NOFO2015 emulsion. As a point of comparison, during the tank experiment, the thinner mean thickness detected from the index was $125 \mu \mathrm{m}$. It corresponds to an unstable emulsion (made with a mix of HC1541 and heavy oil-fuel, different from the NOFO2015 one).

A sensitivity analysis to various parameters is given in Table 6 . The first part of the table, in bold-italics, corresponds to the sensitivity to the number of pixels for the thick part of the slick in the tank. For each number (the nominal one 2537 and a lower and a larger one) and for a thickness equal to $0.025 \mathrm{~mm}$ for the thin part of the slick in the tank, the corresponding thickness for the thick part of the slick, the percentage of the poured volume corresponding to the thin and thick part, respectively, are deduced. Just below, the corresponding volumes are assessed for the NOFO2015 airborne image. A similar approach is taken in the second part of the table in italics corresponding to the sensitivity to the thickness of the thin part of the slick. Thickness for the thick part of the slick in the tank, percentage of volumes for the tank case, and volume for the NOFO2015 airborne image are derived from the thickness for the thin part of the slick in the tank for three cases $0.025,0.05$, and $0.125 \mathrm{~mm}$ (and for a pixel number for the thick part of the slick in the tank equal to the nominal one). The third and last part of the table, in bold, is to compare to the second one in italics. It illustrates the impact of an error of $50 \mathrm{ml}$ on the emulsion volume poured in the tank.

The $0.125-\mu \mathrm{m}$ thickness case for the thin part of the slick appears less realistic than the other two regarding the volume percentage for both the thin and thick part of the slick. The minimum and maximum volumes found in this table for the NOFO2015 image are 15.9 and $21.5 \mathrm{~m}^{3}$, respectively, compared with a nominal assessment about $18 \mathrm{~m}^{3}$.

Even if a tank experiment cannot be easily done again, a laboratory characterization of the Oseberg crude oil would enable us to assess its attenuation coefficient, and therefore a thickness 
Table 6 Volume assessment sensitivity to number of thick pixels (bold-italics), to the thickness assumption for thin pixels (italics), and to the knowledge on the total volume (bold).

Tank experiment with $500 \mathrm{ml}$ poured

\begin{tabular}{|c|c|c|c|}
\hline Number of thick pixels & 2537 & 2000 & 3000 \\
\hline Corresponding thickness for thick part of the slick $(\mathrm{mm})$ & 1.10 & 1.39 & 0.93 \\
\hline Volume for thin part (\%) & 10.7 & 11.2 & 10.4 \\
\hline Volume for thick part (\%) & 89.3 & 88.8 & 89.6 \\
\hline \multicolumn{4}{|c|}{ Volumes $\left(\mathrm{m}^{3}\right)$ derived for the NOFO2015 airborne image } \\
\hline For the thin part & 2.7 & 2.7 & 2.7 \\
\hline For the thick part & 14.9 & 18.8 & 12.6 \\
\hline Total & 17.6 & 21.5 & 15.4 \\
\hline \multicolumn{4}{|c|}{ Tank experiment with $500 \mathrm{ml}$ poured } \\
\hline Thickness for thin part of the slick (mm) & 0.025 & 0.050 & 0.125 \\
\hline Corresponding thickness for thick part of the slick $(\mathrm{mm})$ & 1.10 & 0.97 & 0.57 \\
\hline Volume for thin part (\%) & 10.7 & 21.5 & 53.7 \\
\hline Volume for thick part (\%) & 89.3 & 78.5 & 46.3 \\
\hline \multicolumn{4}{|c|}{ Volumes $\left(\mathrm{m}^{3}\right)$ derived for the NOFO2015 airborne image } \\
\hline For the thin part & 2.7 & 5.5 & 13.6 \\
\hline For the thick part & 14.9 & 13.1 & 7.7 \\
\hline Total & 17.6 & 18.5 & 21.3 \\
\hline \multicolumn{4}{|c|}{ Tank experiment if $450 \mathrm{ml}$ poured instead of $500 \mathrm{ml}$} \\
\hline Thickness for thin part of the slick (mm) & 0.025 & 0.050 & 0.125 \\
\hline Corresponding thickness for thick part of the slick (mm) & 0.98 & 0.84 & 0.45 \\
\hline Volume for thin part (\%) & 11.9 & 23.9 & 59.7 \\
\hline Volume for thick part (\%) & 88.1 & 76.1 & 40.3 \\
\hline \multicolumn{4}{|c|}{ Volumes $\left(\mathrm{m}^{3}\right)$ derived for the NOFO2015 airborne image } \\
\hline For the thin part & 2.7 & 5.5 & 13.6 \\
\hline For the thick part & 13.2 & 11.4 & 6.0 \\
\hline Total & 15.9 & 16.9 & 19.7 \\
\hline
\end{tabular}

assessment could be done for the thin part of the marine tank slick of NOFO2015 emulsion by modeling. It could also be compared with the relative thickness assessed according to Eq. (2) of Ref. 25.

Although it is not perfectly rigorous in the case of an emulsion, the simple transmission measurement in the laboratory has been converted into the attenuation coefficient stored in the extended database, and a skin depth (corresponding to the theoretical att_MAX thickness) has been derived (a more adequate measurement providing the absorption coefficient can be found in Ref. 26). The skin depth of the extended database is about $0.2 \mathrm{~mm}$ in the NOFO2015 emulsion case. The analysis of spectra has shown ${ }^{15}$ that the actual thickness is higher than the skin depth. 
Therefore, the skin depth could be taken as the lower bound of the actual thickness for the NOFO2015 airborne image.

\subsection{Comparison with Other Volume Assessment}

A method for assessing volume of oil on water relying on its visual appearance is well known in the offshore community. It corresponds to a code, named Bonn Agreement Oil Appearance Code (BAOAC), ${ }^{27}$ linking the visual appearance of the oil slick to a thickness range. Although this code is not adequate for emulsion, a volume assessment has been made relying on image photointerpretation. ${ }^{16}$ The corresponding results are reported in Table 7 . Class 3 corresponds to code 3 when the surface appears "metallic" and thickness is in the range 5 to $50 \mu \mathrm{m}$. Class 4 corresponds to code 4 when the surface appears with discontinuous true color and its thickness is between 50 and $200 \mu \mathrm{m}$. Class 5 corresponds to emulsion and thus does not correspond to code 5 when the surface appears with continuous true color, but the code 5 lower limit of $200 \mu \mathrm{m}$ is taken into account in the volume assessment.

The slick surface found using photointerpretation is larger than the one found using the index. The sum of class 3 and class 4 surfaces is much larger than the surface corresponding to the thin part of the slick for the index. The surface for class 5 and the thick part of the slick are of the same order of magnitude. As no thickness range is available for class 5, its contribution to the total volume is probably highly underestimated.

There is a need to connect the thin part of the slick to class 3 and class 4, to consolidate the thickness for the thin part(s), and to update the thickness for the thick part if necessary. According to the tank experiment, taking $1.1 \mathrm{~mm}$ as the approximate thickness for the thick part of the slick implies the selection of $0.025 \mathrm{~mm}$ for its thin part. This is why these values appear with the font (italics) in Table 7 and the corresponding volumes are added to estimate the approximate volume. The thickness upper bound for the thin part of the slick is just taken as the mean thickness of class 4 , which also corresponds to a thickness that has been detected using the index.

The translation of the Bonn code thickness ranges into mean thickness that was made by $\mathrm{Hu}$ et al. $^{28}$ cannot be used in or adapted to the NOFO2015 emulsion case. Indeed, the correspondence between reflectance and thickness is, at least, product specific. In the thickness range obtained during our laboratory measurements, the NOFO2015 emulsion reflectance remains the same. Therefore, in contrast to $\mathrm{Hu}$ et al., ${ }^{28}$ it is not possible to establish a relation between reflectance and thickness by referring to laboratory measurements and transferring it to an image. The cumulative histograms have been computed as by $\mathrm{Hu}$ et al. ${ }^{28}$ to check their shape and the possible identification of classes from inflection points. They are presented in Fig. 12 for the two VNIR wavelengths (470 and $670 \mathrm{~nm}$ ) used for the FI index and for the two SWIR wavelengths (1240 and $1640 \mathrm{~nm}$ ) used by Hu et al. ${ }^{28}$ The histogram obtained for $470 \mathrm{~nm}$ would suggest two classes for the emulsion. It is difficult to identify classes for the other wavelengths.

Table 7 Slick surfaces and volumes for the NOFO2015 airborne image.

\begin{tabular}{llcccc}
\hline \hline & & Thin & Thick & Total \\
\hline Extented database & Surface $\left(\mathrm{m}^{2}\right)$ & 109,007 & 13,533 & 122,540 \\
& Thickness $(\mathrm{mm})$ & 0.025 to 0.125 & 0.2 to 1.1 & \\
& Volume $\left(\mathrm{m}^{3}\right)$ & \multicolumn{2}{c}{2.7 to 13.6} & 2.3 to 14.9 & $5<V \approx 17.6$ \\
\hline & & & Class 4 & Class 5 & Total \\
\hline Bonn code & Surface $\left(\mathrm{m}^{2}\right)$ & 77,147 & 60,440 & 11,347 & 148,934 \\
& Thickness $(\mathrm{mm})$ & 0.005 to 0.050 & 0.050 to 0.200 & $>0.200$ & \\
& Volume $\left(\mathrm{m}^{3}\right)$ & 0.4 to 3.9 & 3 to 12.1 & $>2.3$ & $>5.7$ to 18.2 \\
\hline \hline
\end{tabular}



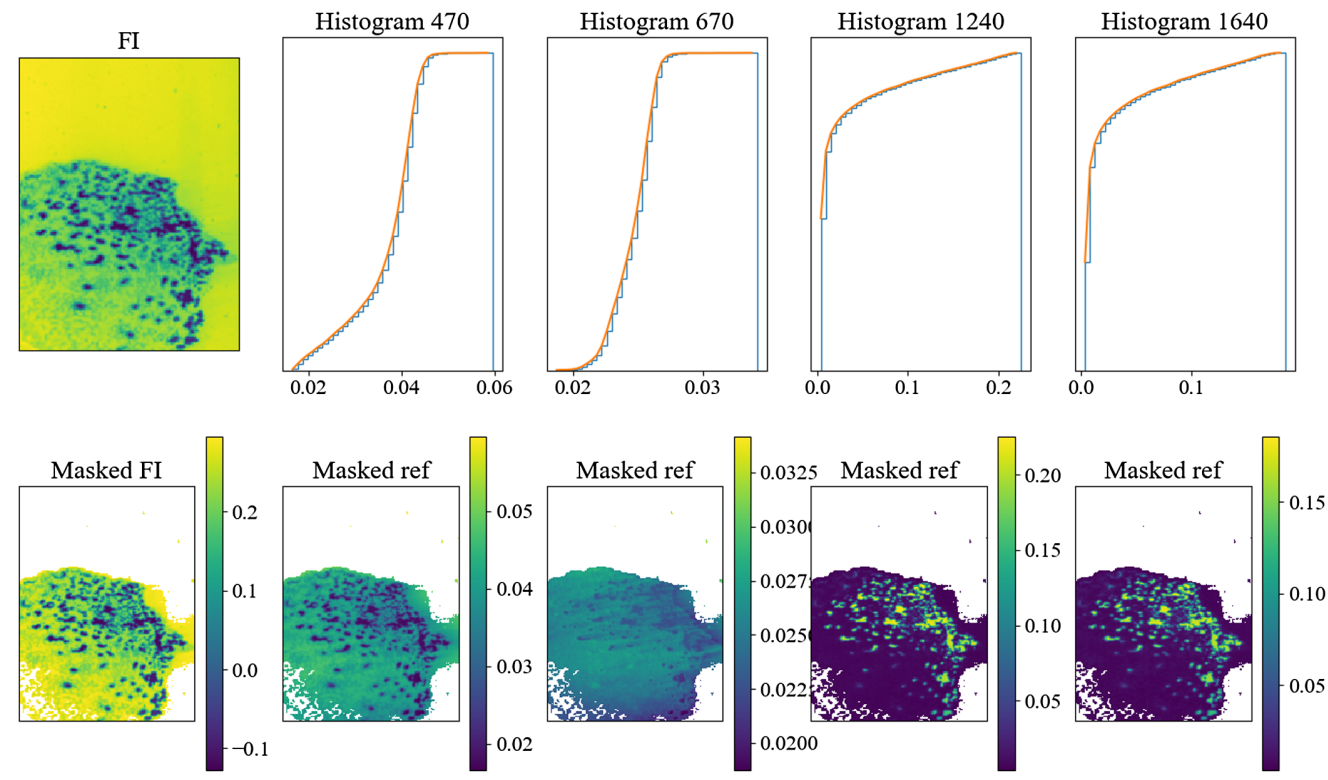

Fig. 12 Cumulative histogram for the VNIR wavelengths included in the FI index and the two SWIR wavelengths used in Ref. 28.

Despite the uncertainty about the thickness of the thinner part of the slick and the effect of the wind and the Langmuir circulation, the laboratory and tank measurements enable one to provide a lower bound and a possible value for the slick volume, whereas the Bonn code only provides a range for the lower bound. They provide a minimum and a possible volume for the thicker part of the slick, which is usually the most important part to collect.

\section{Conclusion}

The work performed in the laboratory or during the tank experiment leads to a database giving access to a large set of properties for various products, ranging from spectral signatures to spectral attenuation coefficient to thicknesses including theoretical minimal, maximal thicknesses from an optical point of view, as well as thicknesses derived from the tank experiment. This extended database is used for product identification and, in case of opaque oil or water-in-oil emulsion layer, for quantification assessment resulting from thicknesses deduced from laboratory and tank experiment measurements.

The presented approach for detection, identification, and quantification is a prototype and needs to be extended for a broader applicability. An operational method would require a much more exhaustive list of products in the database. This would be enough to obtain an efficient solution for slick monitoring with hyperspectral sensors as long as the spatial resolution is suited to the slick size. As observed in this paper, the spatial resolution of airborne hyperspectral cameras is in general appropriate for the monitoring of oil slicks, and following from that, the use of UAV mounted hyperspectral cameras should be an effective monitoring tool. For space-borne hyperspectral sensors, the signal-to-noise ratio and the moderate spatial resolution would probably affect the results. A complementary study needs to be done to simulate images with lower spatial resolution and to assess the impact of this parameter.

The representativeness of the database content can be improved from modeling and should then enable adaptation of the magnitude of spectral signature to a non-flat water surface.

Beyond the database, modeling can be used to define optimal observation conditions to assess the expected contrast between water and oil and the thickness as far as it is in theoretical min-max range from an optical point of view.

Hyperspectral imagery can be an advantage for identification and enables quantification by an optical model for some products. In the case of a known product, detection can be performed with multispectral imagery, and quantification can be achieved from the thickness derived from a 
tank experiment. This opens the presented methodology to multispectral space-borne imagery with higher spatial resolution than the hyperspectral one.

\section{Acknowledgments}

We wish to acknowledge the main colleagues in charge of the NAOMI project on TOTAL side, Dominique Dubucq and Véronique Miegebielle, for bringing the project and their experience about the topic and oils and for providing the photointerpretation of the image. We also wish to acknowledge NOFO for enabling airborne imagery during the 2015 experiment and CEDRE for working with us for the tank experiment.

\section{References}

1. R. Goodman, "Overview and future trends in oil spill remote sensing," Spill Sci. Technol. Bull. 1, 11-21 (1994).

2. M. F. Fingas and C. E. Brown, "Review of oil spill remote sensing," Spill Sci. Technol. Bull. 4, 199-208 (1994).

3. E. A. Cloutis, "Spectral reflectance properties of hydrocarbons: remote-sensing implications," Science 245, 165-168 (1989).

4. F. Kühn, K. Oppermann, and B. Hoerig, "Hydrocarbon index—an algorithm for hyperspectral detection of hydrocarbons," Int. J. Remote Sens. 25, 2467-2473 (2004).

5. G. Andreoli et al., "Hyperspectral analysis of oil and oil-impacted soils for remote sensing purposes," 2013, https://ec.europa.eu/jrc/en/publication/eur-scientific-and-technical-researchreports/hyperspectral-analysis-oil-and-oil-impacted-soils-remote-sensing-purposes (accessed 6 November 2019).

6. M. Lennon et al., "Detection and mapping of the November 2002 Prestige tanker oil spill in Galicia, Spain, with the airborne multispectral CASI sensor," in 3rd EARSEL Workshop Imaging Spectrosc., pp. 245-251 (2003).

7. R. N. Clark et al., "A method for quantitative mapping of thick oil spills using imaging spectroscopy," USGS Report, 2010, https://pubs.usgs.gov/of/2010/1167/ (accessed 6 November 2019).

8. I. Leifer et al., "State of the art satellite and airborne marine oil spill remote sensing: application to the BP Deepwater Horizon oil spill," Remote Sens. Environ. 124, 185-209 (2012).

9. V. Byfield and S. R. Boxall, "Thickness estimates and classification of surface oil using passive sensing at visible and near-infrared wavelengths," in Proc. IGARSS, pp. 14751477 (1999).

10. Z. Otremba, "The impact on the reflectance in VIS of a type of crude oil film floating on the water surface," Opt. Express 7(3), 129-134 (2000).

11. T. Lammoglia and C. Roberto de Souza Filho, "Spectroscopic characterization of oils yielded from Brazilian offshore basins: potential applications of remote sensing," Remote Sens. Environ. 115, 2525-2535 (2011).

12. M. Wettle et al., "Assessing the effect of hydrocarbon oil type and thickness on a remote sensing signal: a sensitivity study based on the optical properties of two different oil typesand the HYMAP and QuickBird sensors," Remote Sens. Environ. 113, 2000-2010 (2009).

13. C. D. Mobley, Light and Water: Radiative Transfer in Natural Waters, Academic Press, 1994. http://www.oceanopticsbook.info/view/references/publications (accessed 7 November 2019).

14. F. E. Nicodemus et al., "Geometrical considerations and nomenclature for reflectance," Report of U. S. Department of Commerce, National Bureau of Standards (1977).

15. F. Viallefont-Robinet et al., "Analysis of water-in-oil emulsion hyperspectral signature: contribution of tank experiment," Proc. SPIE 10784, 107840C (2018).

16. L. Roupioz, F. Viallefont-Robinet, and V. Miegebielle, "Oil slick volume estimation from combined use of airborne hyperspectral and tank experiment data," in Proc. IGARSS (2019).

17. S. Angelliaume et al., "Hyperspectral and radar airborne imagery over controlled release of oil at sea," Sensors 17, 1-21 (2017). 
18. dominique.dubucq@total.com.

19.veronique.miegebielle@total.com.

20. pierre-yves.foucher@onera.fr

21. francoise.viallefont@onera.fr.

22. V. Achard and C. Elin, "Automatic mapping of hydrocarbon pollution based on hyperspectral imaging," in Proc. IGARSS (2019).

23. C. Chang, "An information-theoretic approach to spectral variability, similarity, and discrimination for hyperspectral image analysis," IEEE Trans. Inf. Theory 46(5), 1927-1932 (2000).

24. S. Barstow, "The ecology of Langmuir circulation: a review," Mar. Environ. Res. 9, 211-236 (1983).

25. S. Sun and C. Hu, "The challenge of interpreting oil-water spatial and spectral contrasts for the estimation of oil thickness: examples from satellite and airborne measurements of Deepwater Horizon oil spill," IEEE Trans. Geosci. Remote Sens. 57, 2643-2658 (2019).

26. Y. Lu et al., "Optical interpretation of oil emulsions in the ocean - Part I: laboratory measurements and proof-of-concept with AVIRIS observations," Remote Sens. Environ. 230, 111183 (2019).

27. "The Bonn agreement oil appearance code," https://www.bonnagreement.org/publications (accessed 3 December 2019).

28. C. Hu et al. "Remote sensing estimation of surface oil volume during the 2010 Deepwater Horizon oil blowout in the Gulf of Mexico: scaling up AVIRIS observations with MODIS measurements," J. Appl. Remote Sens. 12(2), 026008 (2018).

Françoise Viallefont-Robinet obtained her diploma in engineering physics in 1987 and has worked for over 20 years in the field of Earth observation optical satellites. She was involved in image quality assessment mainly for modulation transfer function and defocus assessment before moving on to activities linked to physics of measurement, such as radiometric calibration for airborne or space-borne sensors, and subsequently joining the NAOMI project with responsibility for optics for the offshore section.

Laure Roupioz holds a PhD in remote sensing and works as a research engineer in the field of Earth observation. She has more than 10 years of experience in processing optical satellite, LiDAR, and GIS data for applications ranging from land surface reflectance and temperature retrieval to oil spill analysis. Within the NAOMI project, she was in charge of developing a processing chain for the detection, characterization, and quantification of oil slicks from hyperspectral images.

Karine Caillault obtained her $\mathrm{PhD}$ in physical methods in remote sensing. She has been working for 20 years on the physical modelling of the radiation of the natural background: atmosphere, clouds, aerosols, soils and sea surface. She participated in the development of the sea surface radiation model integrated into the Matisse atmospheric propagation code. In the NAOMI project, she was in charge of modelling the radiation of an oil layer on the marine surface.

Pierre-Yves Foucher received his $\mathrm{PhD}$ in atmospheric and Earth science for his work on atmospheric greenhouse gases. Currently, his main research and activities are linked to the analysis of industrial plumes and pollutant releases. He has been part of the French National Research Agency (ANR) project POLLUPROOF (2014-2018) dealing with hazardous noxious substances remote sensing at sea and was responsible for the whole NAOMI project on the ONERA side. 